Original Article

\title{
COMPARATIVE EVALUATION OF ANTIMICROBIAL SUSCEPTIBILITY PATTERN AND VIRULENCE FACTORS AMONG ESBL AND NON- ESBL PRODUCING ESCHERICHIA COLI
}

\author{
Shilpa Shenoy ${ }^{1}$, Sumathi K. ${ }^{2} \&$ A. Veena Shetty ${ }^{3}$ \\ ${ }^{1}$ Research Scholar, Nitte University Centre for Science Education \& Research, ${ }^{3}$ Associate Professor, Department of \\ Microbiology, K. S. Hegde Medical Academy, Nitte University, Mangalore 575018, ${ }^{2}$ Assistant Professor, Department of \\ Mathematics, Manipal Institute of Technology Manipal University, Manipal - 576104, India. \\ Correspondence : \\ A. Veena Shetty \\ Associate Professor, Department of Microbiology, K. S. Hegde Medical Academy, Nitte University, Mangalore 575018, India \\ Mobile : +9194485 45811 E-mail : vndshetty@yahoo.co.in
}

\section{Abstract :}

Objectives: The present study was carried out to compare the antimicrobial susceptibility pattern and phenotypic characteristics in ESBL and non-ESBL producing clinically isolated E.coli.

Material and Methods: A total of 100 non-duplicate consecutive isolates of E.coli were collected from various clinical specimens obtained from K.S. Hegde Charitable Hospital, Mangalore. All the isolates were studied for antimicrobial susceptibility pattern using modified Kirby-Bauer method. ESBL production was screened phenotypically by an initial screening test, which was followed by confirmatory Double disk synergy test. These isolates were screened for virulence factors such as Biofilm assay, hemolysin production and Congo red agar to detect the invasiveness of the isolates.

Result : Out of the 100 E.coli isolates, 45(45\%) isolates exhibited ESBL production. Among the ESBL producing isolates $62 \%$ were haemolytic, 77\% exhibited Congo red uptake, and these two factors were statistically significant as compare non ESBL producing isolates, while $47 \%, 35 \%$ and $18 \%$ of the isolates exhibited high, moderate and low biofilm forming ability, respectively. The ESBL producing isolates were multi-drug resistant. There was statistical significance among the ESBL production and expression of virulence factors

Conclusion : The present investigation revealed, a high prevalence of multiple virulence factors among the ESBL in addition to multidrug resistance when compared with non - ESBL isolates. This indicates a dire need for effective ESBL surveillance and control in the hospitals and judicious use of antibiotics among the general public.

Keywords : Extended Spectrum beta lactamases, E.coli, Biofilm, curli fimbriae, hemolysin

\section{Introduction:}

The advances in the field of antimicrobials have not been sufficient to curb the persistently growing population of multidrug resistant bacteria. These multidrug resistant bacteria remain the major threat to public health worldwide. E.coli is one of the major forerunners in causing

the nosocomial and

\begin{tabular}{|c|}
\hline Access this article online \\
\hline Quick Response Code \\
\hline
\end{tabular}

community acquired infections. It is a commensal in the human intestinal tract. While most strains of E.coli reside harmlessly in the human colon and appear to be poorly adapted to cause disease in healthy individuals, there exist a plethora of pathotypes that can cause specific type of illness in normal hosts and those with compromised nonspecific defence mechanisms ${ }^{1}$. Bacteria are endowed with certain special characters which help them in proliferation and to cause life threatening infections in humans. Pathogenic strains differ from commensal organisms in that they produce virulence factors specific for each pathotype ${ }^{1}$ and the term virulence refers to a quantitative measure of the pathogenicity or the likelihood of a pathogen causing infection. ${ }^{2}$ However, virulence factors (VFs) apply to the elements (i.e. gene products) that enable a microorganism to colonize a host niche where the organism proliferates and causes tissue 
damage or systemic inflammation. Furthermore it has now come to our understanding that virulence is not a separate microbial characteristic but, rather, a complex, dynamic, and changeable phenomenon that includes both host and microbial factors. ${ }^{3}$

The infections caused by E.coli are intestinal infections and extra intestinal i.e. Urinary tract infections (UTIs), bacteraemia, neonatal meningitis, osteomyelitis, peritonitis, cholangitis and other soft tissue infections. In intestinal tract it causes diarrhoeal disorders which may be attributed to various toxins produced by it. Along with the numerous VFs it also has developed resistance to numerous antimicrobial agents, especially the third generation Cephalosporins, which has led to the difficulty in treating the infections caused by these multidrug resistant organisms.

Many studies have been carried out to detect the virulence factors of E.coli. However, very few studies have been conducted on extended spectrum beta lactamase (ESBL) and non ESBL producing isolates. Hence this study was undertaken to compare the virulence factors and antibiotic susceptibility pattern of pathogenic E.coli isolated from nosocomial infections.

\section{Material and Methods :}

A total of 100 non-duplicate isolates of E.coli isolated from various clinical samples of the hospitalized patients were obtained from K.S. Hegde Charitable Hospital, Mangalore. The organisms were identified based on colony morphology, Gram staining and standard biochemical tests. All the isolates were studied for antimicrobial susceptibility pattern using modified Kirby-Bauer method. ESBL production was screened phenotypically by an initial screening test, which was followed by confirmatory Double disk synergy test set by $\mathrm{CLSI}^{4}$ guidelines. Screening for ESBL production was done by placing Cefotaxime $(30 \mu \mathrm{g})$, Ceftazidime $(30 \mu \mathrm{g})$ and Ceftriaxone $(30 \mu \mathrm{g})$ on inoculated Mueller-Hinton agar plates and incubated for 24 hours at $37^{\circ} \mathrm{C}$. When the inhibition zones of the drugs for gram negative bacteria were $\leqslant 27 \mathrm{~mm}$ for Cefotaxime $(30 \mu \mathrm{g}), \leqslant$ $22 \mathrm{~mm}$ for Ceftazidime $(30 \mu \mathrm{g}), \leqslant 25 \mathrm{~mm}$ for Ceftriaxone
$(30 \mu \mathrm{g})$ respectively, the strain was suspected as a potential ESBL producer. The potential ESBL isolate in E.coli was then confirmed using Cefotaxime $(30 \mu \mathrm{g})$, ceftazidime $(30 \mu \mathrm{g})$, alone and in combination with clavulanic acid on Muller hinton agar. The test organism was identified as an ESBL producer when the zone of inhibition of ceftazidime $(30 \mu \mathrm{g})$ or Cefotaxime $(30 \mu \mathrm{g})$ combined with inhibitor showed difference of $\geqslant 5 \mathrm{~mm}$ compared with cephalosporins alone.

\section{Detection of Virulence Factors:}

The above E.coli isolates were screened for the following virulence factors.

1. Haemolysin production: Plate haemolysis test was done by using $5 \%$ sheep blood agar to detect alphahaemolysin produced by E.coli. The bacteria was streaked on sheep blood agar and incubated over night at $35^{\circ} \mathrm{C}$. Haemolysin production was be detected by the presence of a zone of complete lysis of erythrocytes around the colony. ${ }^{5}$

2. Curli fimbriae: The ability to express curli fimbriae was evaluated by streaking each isolate on modified LB-agar plates (without $\mathrm{NaCl}$ ) containing $0.004 \%$ Congo red (CR) and $0.002 \%$ Coomassie Brilliant Blue G. CR binding was indicated by the presence of red or pink colonies after incubation overnight at $37^{\circ} \mathrm{C}$.

3. Biofilm formation in microtitreplates: The ability of the isolates to form biofilm was determined as per the protocol of Rodriguez-Bano et al. ${ }^{7}$ with some minor modifications. Overnight cultures were inoculated into Luria Bertani broth, diluted to 1:100 and incubated for 24 hour at $37^{\circ} \mathrm{C}$ without shaking. Each test was performed in triplicate in 96 well microtitre plates. Negative controls used in each plate were also included in triplicate. Biofilms were stained with crystal violet $1 \%$ $(\mathrm{w} / \mathrm{v})$ and quantified by the Universal microplate reader (Chem Well, Awareness Technology, INC.) at OD630 nm after solubilization with $33 \%$ glacial acetic acid. Isolates were classified as moderate biofilm formers if they had an OD value at least twice that of negative controls and good biofilm formers if their OD value exceeded that of negative controls by a factor of four, as suggested by 
Rodriguez-Bano et al. ${ }^{7}$

Statistical analysis: The results of the study were analyzed by Mann- Whitney $U$ Test and the level of significance was set at $\mathrm{P}<0.05$.

\section{Results:}

The 100 extraintestinal E.coli isolates were collected from various samples such as Urine(65\%), Exudates(pus, pus swab, wound aspirates)(26\%), Body fluid(4\%), and blood(5\%).

Antimicrobial resistance was studied to the commonly used antibiotics. The 100 E.coli isolates studied were found to be susceptible to the carbapenems tested. Among the ESBL producing isolates high susceptibility rates were found among the Nitrofurantoin, Piperacillin Tazobactum and Co-trimaxazole. The commonly used antibiotics were found to be resistant among both ESBL as well as non ESBL groups. Among the 45 isolates in ESBL group 36 isolates exhibited multidrug resistance.

The virulence factors such as hemolysins, curli fimbriae and biofilm formation ability were investigated. The presence of the curl fimbriae $(60 \%)$ was found to be the most common virulence factor among the isolates. The virulence factors were studied comparing two groups among the ESBL and non ESBL producing isolates. Our study found a statistically significant increase of the hemolysin(62\%), curli fimbriae(77\%), presence of multidrug resistance(80\%) and multiple virulence factors $(80 \%)$ among the ESBL producing isolates. Whereas, there was no statistical significance on biofilm forming ability of the isolates.

\section{Discussion :}

The ability of the organism to survive the hostile environments of the host, adhere colonise and cause disease is brought about by the hidden armamentarium of virulence factors endowed on the bacteria. Studies conducted during the early $20^{\text {th }}$ century found that the organisms required the presence of specific microbial determinants which led to the view that there were intrinsic differences between pathogens and nonpathogens and the concept that disease associated microbes were endowed with certain characteristics that enabled them to cause disease. This enabled the investigators to differentiate between pathogenic and non pathogenic bacteria ${ }^{3}$. Our study was an approach to understand the expression of virulence factors under the influence of antimicrobial resistance exhibited by the organism.

\begin{tabular}{|l|c|c|}
\hline \multicolumn{3}{|l|}{$\begin{array}{l}\text { Table 1 : Antibiotic susceptibility pattern of ESBL } \\
\text { producing and non ESBL producing E.coli isolates }\end{array}$} \\
\hline Antibiotics & \multicolumn{2}{|c|}{ Percentage of susceptibility } \\
\hline & ESBL & NON ESBL \\
\hline $\begin{array}{l}\text { Imipenem } \\
\text { Piperacillin/ }\end{array}$ & 100 & 100 \\
\hline tazobactam & 65 & 74 \\
\hline Amikacin & 56 & 64 \\
\hline Chloramphenicol & 36 & 70 \\
\hline Co-trimoxazole & 60 & 68 \\
\hline Ciprofloxacin & 45 & 69 \\
\hline Ertapenem & 100 & 100 \\
\hline Nitrofurantoin & 77 & 78 \\
\hline Ceftazidime & 0 & 84 \\
\hline Ceftriaxone & 32 & 85 \\
\hline Cefotaxime & 30 & 82 \\
\hline Gentamycin & 52 & 74 \\
\hline
\end{tabular}

\begin{tabular}{|c|c|c|c|c|}
\hline $\begin{array}{l}\text { Sl. } \\
\text { no }\end{array}$ & Virulence Factors & $\begin{array}{c}\text { ESBL isolates } \\
45(45 \%)\end{array}$ & $\begin{array}{c}\text { Non ESBL isolates } \\
55(55 \%)\end{array}$ & $P$ value \\
\hline 1 & Hemolysis & $28(62 \%)$ & $6(11 \%)$ & $\begin{array}{c}.000 \\
\text { Highly significant }\end{array}$ \\
\hline 2 & Curli assay & $35(77 \%)$ & $25(46 \%)$ & $\begin{array}{c}0.001 \\
\text { Highly significant }\end{array}$ \\
\hline 3 & $\begin{array}{l}\text { Biofilm formation } \\
\text { High } \\
\text { Moderate } \\
\text { Low }\end{array}$ & $\begin{array}{c}21(47 \%) \\
16(35 \%) \\
8(18 \%)\end{array}$ & $\begin{array}{c}18(33 \%) \\
28(51 \%) \\
9(16 \%)\end{array}$ & $\begin{array}{c}\text { Not } \\
\text { significant }\end{array}$ \\
\hline 4 & Multidrug resistance & $36(80 \%)$ & $18(32 \%)$ & $\begin{array}{c}0.000 \\
\text { Highly significant } \\
\end{array}$ \\
\hline 5 & $\begin{array}{l}\text { Strains exhibiting } \\
\text { multiple virulence } \\
\text { factors }\end{array}$ & $36(80 \%)$ & $22(42 \%)$ & $\begin{array}{c}0.000 \\
\text { Highly Significant }\end{array}$ \\
\hline
\end{tabular}


Antibiotic susceptibility studies brought to light the higher resistance among the commonly used antibiotics. Along with third generation cephalosporins, amikacin and Chloramphenicol exhibited higher resistance to the antibiotics tested. The greater prevalence of resistance to common antibiotics may be due to the excessive use and misuse by the healthcare personnel. Similar trend has been reported by different group of investigators ${ }^{5,8}$. Our study indicated a high rate of ESBL production by E.coli which may be due to the selective pressure imposed by extensive use of antimicrobials. The indiscriminate use and misuse of cephalosporins is responsible for the high rate of selection of ESBL producing microorganisms. These results are consistent with previous studies from India. ${ }^{5,9,10}$ This trend can be only managed by constant and consistent screening and surveillance of the isolates.

Our study brought to light that the ESBL producing strains expressed virulence factors significantly higher than the non ESBL isolates. We studied the adhesive property of the organism by fimbrial adhesins such as curli fimbriae. These are one among the numerous adhesins possessed by the organism. It is a known fact that the adhesins are the first line of virulence factors which help the organism to colonise the host and establish itself. ${ }^{11}$

E. coli cells associated with a surface generally clump together to form microcolonies or biofilm in order to maximize metabolic breakdown and stress management. ${ }^{12}$ The bacterial interaction with a surface is a two-stage process. ${ }^{13}$ Bacterial cells can easily be removed from the surface during the first phase. In the second phase Bacterial association with the surface becomes irreversible. The formation of biofilm is seen during this phase as the cells multiply and produce polysaccharide. E. coli produce a long, thin and wiry surface fibre known as curli and polysaccharide. ${ }^{14,15,16}$ Curli plays an important role in the adhesion of E. coli to its contact hosts. ${ }^{17}$ There is specific interaction with host matrix proteins such as fibronectin, laminin and plasminogen to initiate adherence and colonization in the host. ${ }^{18,19.20}$ Prior research suggests that curli may also play a role in the development of biofilm on inert surfaces. ${ }^{21,22}$ The curli-expressing cells form red, while noncurli-expressing cells form colourless colonies on the indicator agar.

We found that expression of curli fimbriae was seen $77 \%$ in ESBL producing isolates as compared to $46 \%$ non - ESBL producing isolates. The difference was statistically significant in the ESBL group. The production of Curli fimbriae and the co existence of ESBL production has not been undertaken earlier to discuss in detail. Curli fimbriae has been associated with virulence and pathogenicity among several bacterial species including E.coli causing avian septicaemia ${ }^{23}$ and UPEC strains ${ }^{24}$. But our study reveals the fact that the antimicrobial resistance confers additional resistance abilities to the organism. The biofilm production has been of major concern since its discovery on medical catheters and implants. A structured consortium consisting of bacterial DNA, polysaccharide and protein is a biofilm. Bacterial biofilms have known to cause chronic illness in the medical setting resulting in increased resistance to the antimicrobial agents and disinfectants used in the medical world ${ }^{25}$. We studied the biofilm formation of the isolates on microtitreplate method as described by Rodrigez Bano et al. We also made an effort to semiquantitate the biofilm formation by identifying the isolates forming High, moderate and low biofilm forming isolates. In our study we found that biofilm forming ability of ESBL and Non ESBL were not statistically significant but both were fairly positive to form biofilms. It is also noteworthy that Non ESBL forming organisms were not far behind in forming biofilms. It has been noted that catheters and other medical devices colonization and biofilm formation occurs in many patients undergoing invasive treatment, from a very early stage. ${ }^{25}$ Hence the detection of the biofilm on medical catheters and its proper treatment is necessary to minimize the colonization and infection by the pathogens.

Production of cytotoxic toxins is common phenomenon among the pathogenic bacteria. ${ }^{26}$ The more severe form of E.coli infections are usually associated with hemolysin production by the organism. Hemolysins are known to have 
numerous effects on host tissues including inflammation, tissue injury and impaired host defenses. ${ }^{27}$ Hemolysin production among isolates during our investigation showed significantly higher presence among the ESBL isolates confirming that multi drug resistance contributes to higher expression of virulence factors. A recent study also found significant percentage of hemolysin production among the multi drug resistant E.coli. ${ }^{8}$

The drug resistance is on an alarming rise. The resistance may provide a substantial advantage to the survival of the

\section{References:}

1. Donnenberg MS. Enterobacteriaceae. In: Mandell GL, Bennet JE, Dolin R. Principles and Practice of Infectious Diseases. 6th edition. Churchill Livingstone. 2005: 2567-86

2. Raksha R, Srinivasa H, Mecaden RS. Occurrence and characterization of uropathogenic E.coli in urinary tract infections. Indian J Med Microbiol 2003; 21: 102-7.

3. Arturo Casadevall and Liise-anne Pirofski. Host-Pathogen Interactions The Attributes of Virulence. J. Infect. Dis 2001;184:337-44

4. Clinical and Laboratory Standards Institute. Performance Standards for Antimicrobial Susceptibility Testing: Twenty Second Informational Supplement M100-S22. Wayne, PA, USA: CLSI; 2012

5. S.Sharma, G.K Bhat, S Shenoy .Virulence factors and Drug resistance in Escherischia coli isolate from Extra intestinal infections. Indian J Med Microbiol,2007,25(4):369-79.

6. Grozdanov L, Raasch C, Schulze J, Sonnenborn U, Gottschalk G, Hacker J \& Dobrindt U (2004) Analysis of the genome structure of the nonpathogenic probiotic Escherichia coli strain Nissle 1917. J Bacterio 186: 5432-5441.

7. Rodriguez-Bano J, Marti S, Soto S, Fernandez-Cuenca F, Cisneros JM, Pachon J, Pascual A., Martinez-Martinez L.,McQueary C., Actis L.A., Vila J. Biofilm formation in Acinetobacter baumannii: associated features and clinical implications. Clin Microbiol Infect 2008 14: 276-8.

8. Mittal S, Sharma M, Chaudhary U. Study of virulence factors of uropathogenic Escherichia coli and its antibiotic susceptibility pattern. Indian J Pathol Microbiol 2014;57:61-4.

9. Bradford PA. Extended spectrum ß-lactamases in 21st century: Characterization, epidemiology and detection of this important resistance threat. Clin Microbiol Rev 2001;:933-51.

10. Anathakrishan AN, Kanungo R, Kumar A, Badrinath S. Detection of extended spectrum ß-lactamase producers among surgical wound infections and burn patients in JIPMER. Indian J Med Microbiol 2000;18:160-5.

11. Shetty AV, Kumar SH, Shekar M, Shetty AK, Karunasagar I, Karunasagar I. Prevalence of adhesive genes among uropathogenic Escherichia coli strains isolated from patients with urinary tract infection in Mangalore. Indian J Med Microbiol 2014;32:175-8.

12. Berkhoff HA, Vinal AC. Congo red medium to distinguish between invasive and non-invasive Escherichia coli pathogenic for poultry. Avian Dis 1985;30:117-21.

13. Silveira WD, Benetti F, Lancellotti M, Ferreira A, Solferini VN, Brocchi M. Biological and genetic characteristics of uropathogenic Escherichia colistrains. Rev Inst Med Trop Sao Paulo 2001;43:303-10.

14. Otto K. and Hermansson M. (2004) Inactivation of ompX causes increased interactions of type 1 Fimbriated Escherichia coli with abiotic surfaces. J Bacteriol 2004,186, 226-234. pathogen in the host resulting in increased morbidity and mortality. Therefore appropriate empirical therapy and judicious use of the antibiotics is a necessary requisite to prevent the resistance among the pathogens. In the present study, ESBL producing E.coli isolates had strong positive correlation with multiple virulence factors. Hence, we feel that multidrug resistance will positively affect the expression of virulence factors. Therefore, the continuous screening of E.coli for the antimicrobial resistance is of utmost importance.

15. Marshall KC, Stout, R, and Mitchell R, Mechanism of the initial events in the sorption of marine bacteria to surfaces. J Gen Microbiol 197168, 337-348.

16. Olsen A, Jonsson A. and Normark S. Fibronectin binding mediated by a novel class of surface organelles on Escherichia coli. Nature 1989, 338, 652-655.

17. Uhlich GA, Keen JE. and Elder R.O.Mutations in the csgD promoter associated with variations in curli expression in certain strains of Escherichia coli 0157:H7. Appl Environ Microbio 2001, 67, 2367-2370.

18. Uhlich GA, Keen JE and Elder RO. Variations in the CsgD promoter of Escherichia coli 0157:H7 associated with increased virulence in mice and increased invasion of HEp-2 cells. Infection and Immunity 2002, 70, 395-399.

19. Gophna U, Oelschlaeger TA, Hacker J. and Ron EZ. Role of Fibronectin in curli-mediated internalization. FEMS Microbiology Letters 2002, 212, 55-58.

20. Arnqvist, A, Olsen A, Pfeifer J, Russell DG and Normark S. The $\mathrm{Cr}$ protein activates cryptic genes for curli formation and fibronectin binding in Escherichia coli HB101. Molecular Microbiology 1992, 6, 2443-2452.

21. Olsen A, Arnqvist A, Hammar M. and Normark S. Environmental regulation of curli production in Escherichia coli. Infectious Agents Diseases 1993, 2, 272-274.

22. Sjobring U, Pohl G. and Olsen A. Plasminogen, absorbed by Escherichia coli expressing curli or by Salmonella enteritidis expressing thin aggregative fimbriae, can be activated by simultaneously captured tissue-type plasminogen activator (t-PA). Molecular Microbiology 1994, 14, 443-452.

23. Vidal O, Longin R, Prigent-Combaret C, Dorel C, Hooreman M. and Lejeune P. Isolation of an Escherichia coli K-12 mutant strain able to form biofilms on inert surfaces: involvement of a new ompR allele that increases curli expression. J Bacteriol 1998, 180, 2442-2449.

24. Prigent-Combaret C, Prensier G, Le Thi T.T, Vidal O, LejeuneP. and Dorel C. Developmental pathway for biofilm formation in curli-producing Escherichia coli strains, role of flagella, curli and colanic acid. Environmental Microbiology 2000, 2, 450-464.

25. Rodney M. Donlan Biofilms and Device-Associated Infections. Emerging Infectious Diseases 2001. 7, No. 2, March-April,277

26. Hacker, J., and C. Hughes. Genetic analysis of bacterial hemolysin production. Bull. Inst. Pasteur 1985, 83:149-165

27. Stanley P, Koronakis V, Hughes C. Acylation of Escherichia coli hemolysin:A unique protein lipidation mechanism underlying toxin function. Microbiol Mol Biol Rev 1998;62:309-33 